11-1-2016

\title{
JMASM40: Monte Carlo Simulations For Structural Equation Modelling (Revolution R)
}

Sarah A. Rose

Wayne State University, rosey13579@gmail.com

Barry Markman

Wayne State University, barry.markman@wayne.edu

Follow this and additional works at: http://digitalcommons.wayne.edu/jmasm

Part of the Applied Statistics Commons, Social and Behavioral Sciences Commons, and the Statistical Theory Commons

\section{Recommended Citation}

Rose, Sarah A. and Markman, Barry (2016) "JMASM40: Monte Carlo Simulations For Structural Equation Modelling (Revolution R)," Journal of Modern Applied Statistical Methods: Vol. 15 : Iss. 2 , Article 43.

DOI: $10.22237 /$ jmasm/1478004060

Available at: http://digitalcommons.wayne.edu/jmasm/vol15/iss2/43

This Algorithms and Code is brought to you for free and open access by the Open Access Journals at DigitalCommons@WayneState. It has been accepted for inclusion in Journal of Modern Applied Statistical Methods by an authorized editor of DigitalCommons@WayneState. 


\section{JMASM40: Monte Carlo Simulations For Structural Equation Modelling (Revolution R)}

Erratum

This paper was originally published in JMASM Algorithms \& Code without its enumeration, JMASM40. 


\section{Monte Carlo Simulations for Structural Equation Modelling (Revolution R)}

\author{
Sarah A. Rose \\ Wayne State University \\ Detroit, MI
}

\author{
Barry Markman \\ Wayne State University \\ Detroit, MI
}

Revolution R code is presented to setup Structural Equation Model (SEM) for a Monte Carlo study. The example is a comparison of different fit indices.

Keywords: Revolution R, structural equation model, SEM, fit indices, RMSEA, SRMR, CFI, chi-squared

Revolution R Lavaan package contains algorithms for performing SEM analytics. It has the ability to perform Monte Carlo simulations. The example considered here is for comparing model fit indices. This algorithm was verified using two wellknown SEM computer software programs by extracting the last repetition of the Monte Carlo simulation in Revolution $\mathrm{R}$ and comparing the output results with IBM SPSS Amos Graphics and with Mplus Version 5.1.

The algorithm was developed for a $4 \times 4$ correlation matrix of random values constrained within a specific range. Lines 4 and 5 of the code indicate the minimum and maximum values of the correlation value range, respectively. These values are defined as variable "b1" for the lower limit and "c1" for the upper limit. Line 6, variable "var", specifies the variant range that increases in magnitude based on the location of the correlation value within the correlation matrix. The algorithm defaults the variant range to zero, so all random correlation values for the matrix are within the same range.

The SEM model was designed for four variables: $X_{1}, X_{2}, X_{3}$, and $X_{4}$. The first three are exogenous variables, and $X_{4}$ is the only endogenous variable. The $4 \times 4$ correlation matrix is specified on line 75 . To modify the correlation matrix to

Dr. Rose is an Adjunct Instructor of Education Evaluation and Research. Email her at: ak1734@wayne.edu. Dr. Markman is a Professor of Educational Psychology and Education Evaluation and Research.Email him at: barry.markman@wayne.edu. 


\section{ROSE \& MARKMAN}

another matrix size (i.e. $3 \times 3$ matrix, or $5 \times 5$ matrix) the variables on lines 7 through 16 would need to be redefined. Furthermore, the SEM model specification within the Monte Carlo command loop would require appropriate modifications on lines 69 through 80 .

The model is specified with no correlation relationships, and no direct paths between variables $X_{1}$ and $X_{2}, X_{1}$ and $X_{3}$, and $X_{2}$ and $X_{3}$. Relationships can be added or modified by deleting or modifying lines 78 through 80 , which are currently designed to force relationship values to zero.

The algorithm was designed to provide six output files for six sample sizes $(50,100,150,200,300$, and 500). To change the sample sizes, modify the variable names and values on lines 18 through 23 . The new variable names will have to be modified accordingly on lines 82 and 140 .

The code provided in this article only contains the Monte Carlo simulation for one sample size of 50. Repetition of the algorithm logic for the other five sample sizes has been deleted to more concisely display the algorithm in this article. The repeated code should be copied and pasted, as appropriate, for compilation of all six output files. To do this, copy lines 68 through 156 for each of the various sample sizes required. The variable "ss50" should be replaced with the appropriate variable names that were specified in lines 19 through 23 (e.g. "ss100", "ss150", "ss200", "ss300", and "ss500"). These variable names should replace "ss50" in the copied version of lines 82,140 , and 156 .

To modify the number of repetitions for the Monte Carlo simulation loop, modify the variable value of "rep" on line 25 .

The model fit indices calculated and provided in the output files are the ChiSquared ("baseline.pvalue" as specified by Revolution R), Root Mean Square Error Approximation (RMSEA), Standardized Root Mean Square Residual (SRMR), and Comparative Fit Index (CFI). The output files indicate the sample size, number of repetitions, mean degrees of freedom for all simulations, specified correlation range, and the percentage of times the SEM resulted in model fit index values above or below a critical value.

The Lavaan Package contains additional model fit indices that can be added to the output file. These include Tucker-Lewis Index (TLI), Goodness of Fit Index (GFI), Adjusted Goodness of Fit Index (AGFI), Normalized Fit Index (NFI), and Nonnormalized Fit Index (NNFI). To add these fit indices, copy lines 98 through 102 and paste them at the end of the repetition loop. Replace references to "srmr" with "tli", "gfi", "agfi", "nfi", or "nnfi", as appropriate. Prepare the output by copying and modifying lines 118 through 120, lines 133 and 134, and lines 148 and 149 appropriately. The new variables created for these model fit indices would 


\section{MONTE CARLO SIMULATIONS FOR SEM (REVOLUTION R)}

require specification of variable length. Insert the appropriate length and zero constant values, after lines 39 and 66, by copying the previous lines and modifying the variable names as appropriate.

Figure 1. $\mathrm{R}$ code and Lavaan package for conducting SEM fit indices

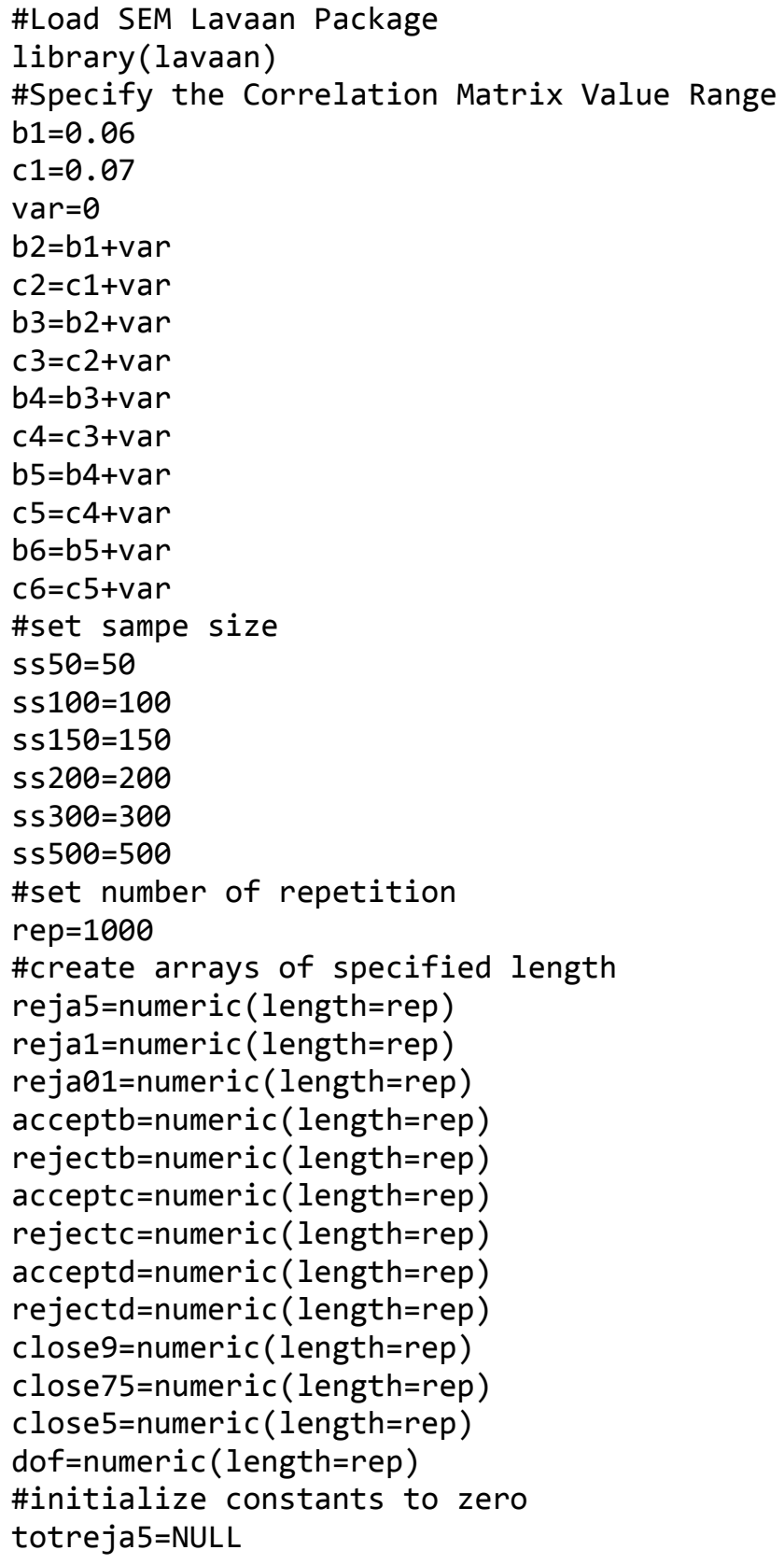




\section{ROSE \& MARKMAN}

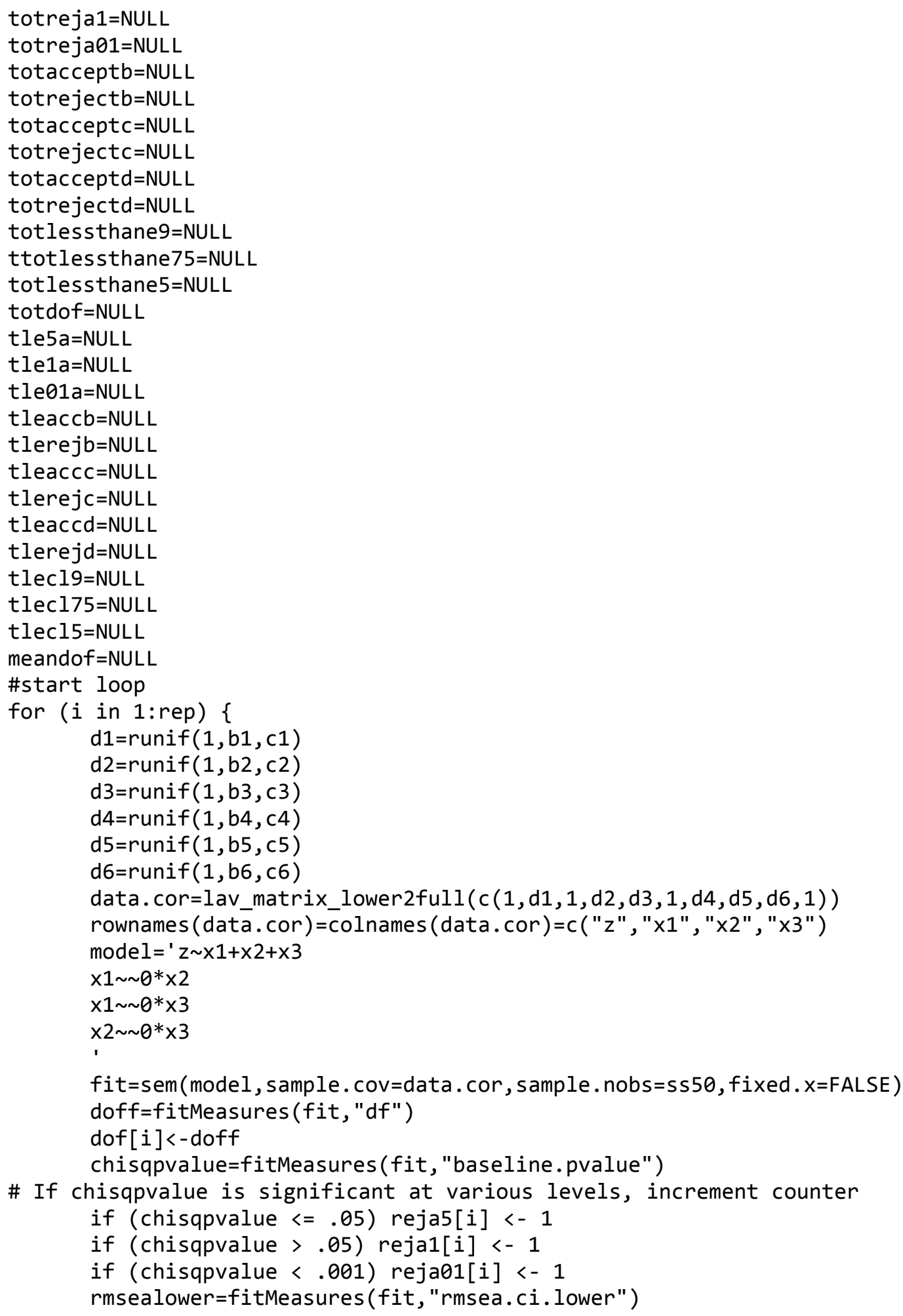




\section{MONTE CARLO SIMULATIONS FOR SEM (REVOLUTION R)}

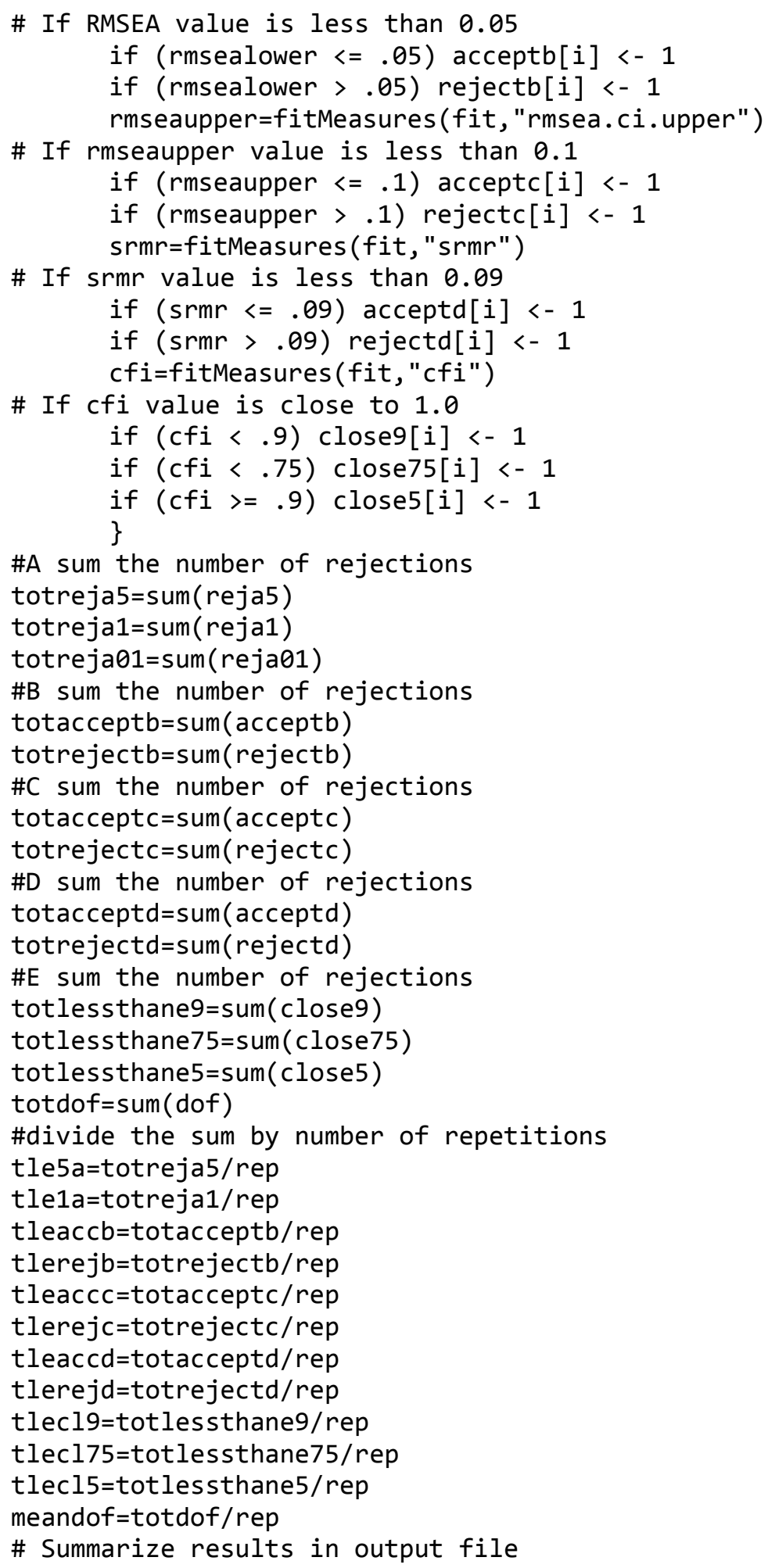




\section{ROSE \& MARKMAN}

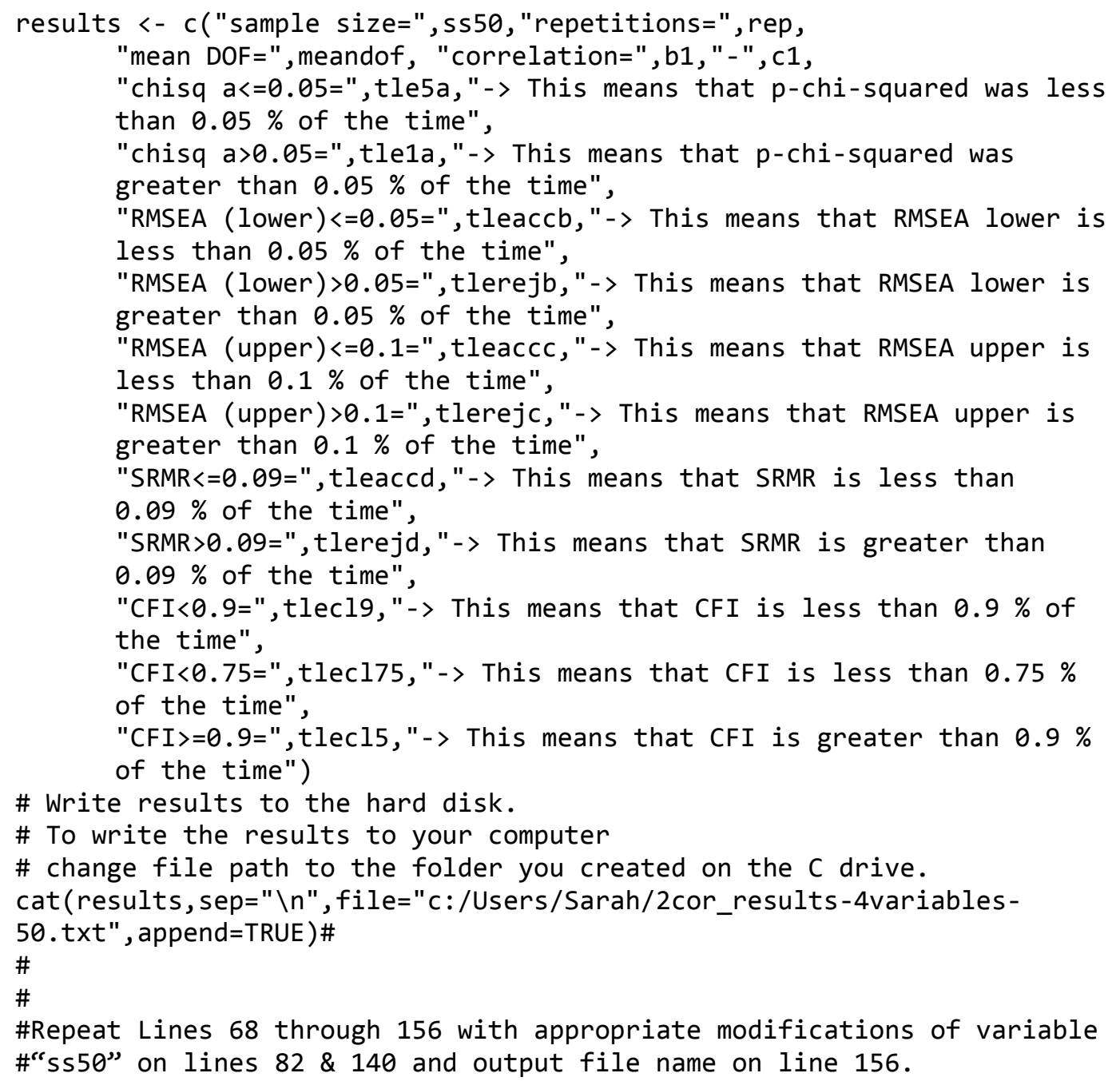

